\title{
ANTONIO CANDIDO LEITOR DE OSWALD DE ANDRADE
}

http://dx.doi.org/10.11606/issn.2237-1184.v0i30p106-119

Maria Augusta Fonseca ${ }^{\mathrm{I}}$

\section{RESUMO}

Este ensaio procura examinar diferentes textos críticos de Antonio Candido sobre Oswald de Andrade envolvendo questionamentos, concordâncias e controvérsias. No conjunto dinâmico dessas reflexões destacam-se suas avaliações pioneiras sobre a obra ficcional de Oswald, alinhadas ao reconhecimento precursor de seu papel fundamental no âmbito do Modernismo brasileiro e de sua grande importância na vida cultural do país.

\section{ABSTRACT}

This essay intends to examine different texts of Antonio Candido's literary criticism on Oswald de Andrade implying inquiries, agreements and controversies. These dynamic reflections hold his pioneer view on Oswald's fictional works also claiming the leading role of this artist amidst the Brazilian Modernism and his great influence in the context of our cultural life.

\section{PALAVRAS-CHAVE:}

Antonio Candido; Oswald de Andrade; produção estética; Modernismo brasileiro; vida cultural.

\section{KEYWORDS}

Antonio Candido; Oswald de Andrade; fictional works; Brazilian Modernism; cultural life.

\footnotetext{
' Universidade de São Paulo, São Paulo, São Paulo, Brasil.
} 
A paisagem desta capital apodrece. Apareço ao leitor. Pelotari. Personagem através de uma vidraça. De capa de borracha e galochas. Foram alguns militares que transformaram a minha vida. Glória dos batizados! Lá fora, quando secar a chuva, haverá o sol.

"Recitativo", in: Serafim Ponte Grande

A

ntes de abordar o tema propriamente dito - "Antonio Candido, leitor de Oswald de Andrade" - cabe um breve preâmbulo que tem por foco nosso homenageado, a saber: Em 26 de abril de 2018 recebi do crítico italiano Roberto Vecchi uma mensagem eletrônica, com um enigmático cabeçalho - "e ainda não faz um ano". Portava um anexo com o registro de um acontecimento inédito em seu dia de trabalho: um grafite no muro do departamento onde Vecchi leciona, na Universidade de Bolonha (Itália), com os seguintes dizeres: "Antonio Candido vive". Orgulhoso de seus alunos, Vecchi fotografou e me enviou a estampa. ${ }^{1}$ Fica a inscrição simbólica, sem protocolo, além das fronteiras.

Feito o registro, passo ao propósito desta leitura ${ }^{2}$ que visa enfeixar textos de Antonio Candido norteadores de suas reflexões sobre Oswald de Andrade (autor e obra), processados ao longo de muitos anos, e marcados por um começo polêmico no rodapé literário da Folha da Manhã, em três artigos datados de 1943, para os quais convergem seriedade crítica e tom desafiante de zombaria. Essa postura do crítico, na contramão de seu procedimento habitual, demanda primeiramente um parêntese explicativo sobre as relações do articulista com o escritor-alvo.

De acordo com Antonio Candido, ele conheceu Oswald no início de 1940 por intermédio de um amigo comum, Paulo Emilio Sales Gomes, que, mesmo bastante jovem, frequentava a casa do já afamado, controverso e combativo escritor modernista, que a partir da década de 1930 tornara-se um militante de esquerda, ligado ao Partido Comunista. Afastado das rodas dos ex-companheiros de 22, e em brutal derrocada financeira, o

\footnotetext{
1 A reprodução do mural, com os devidos créditos, ilustra a capa deste número da revista Literatura e Sociedade em homenagem a Antonio Candido.

${ }^{2} \mathrm{O}$ presente texto foi apresentado no seminário "Antonio Candido e a literatura", em mais uma das homenagens do Departamento de Teoria Lirerária e Literatura Comparda (FFLCH-USP), ao seu fundador, buscando discutir e estimular reflexões sobre sua obra.
} 
escritor era rechaçado por muitos, tanto pelas posições políticas assumidas como pelas atitudes públicas irreverentes ou hostis que mantinha acesas. Por esse tempo era ambígua a relação de Oswald de Andrade com o grupo de jovens acadêmicos da revista Clima (1941-1944), como Décio de Almeida Prado, Ruy Coelho, Paulo Emilio, Antonio Candido, evidenciada por uma recíproca "mistura de estima e agressividade" (CANDIDO, 1995, p. 72). ${ }^{3}$ Isso foi anos mais tarde reafirmado pelo crítico, ponderando que "apesar de nós também estarmos sempre dando bicadas nele, era grande e eu diria quase excepcional no tempo o apreço que manifestávamos por ele e sua obra" (1995, p. 73-74). Uma vez mais, em "Digressão sentimental sobre Oswald de Andrade" (1970), voltou a insistir na relação conflituosa, mas reivindica a visão dianteira do grupo sobre o escritor: "Vistas as coisas com o recuo do tempo, ocorre-me que talvez nenhum outro grupo, na época, se tenha ocupado tanto com a sua obra, quando estava em moda considerálo sobretudo um piadista de gênio - , o que de fato era, sem prejuízo de coisa mais sólida (1995, p. 72).

Para o crítico, uma prova desse reconhecimento seria a transcrição na revista Clima do "admirável artigo satírico 'Antologia'". Cabe notar que no referido texto o escritor explora à exaustão o termo "anta", como prefixo, sufixo e enfixo, subvertendo usos da língua para tecer sua sátira demolidora. Apesar de não entrar nesses detalhes, Candido informa tratarse de um texto que "ele [Oswald] publicara em 1927 contra o grupo nacionalista da 'Anta' (Cassiano Ricardo, Menotti del Picchia, Plínio Salgado etc.)" (1995, p. 74). Tudo leva a crer, porém, que naqueles idos de 1940 o gesto agregador não serviu para atenuar as tensões com o grupo. É sabido que Oswald tachou os rapazes de Clima de "chato-boys". Esse apelido pouco lisonjeiro foi impresso pelo escritor ao rebater com prontidão a crítica desferida por Antonio Candido sobre sua obra e sobre a expectativa de seu novo livro, o primeiro volume de Marco Zero (A revolução melancólica).

Os artigos assinados por Antonio Candido na Folha da Manhã são: "Romance e expectativa" (8 ago. 1943a); "Antes do Marco Zero" (15 ago. 1943b); e "Marco Zero" (29 out. 1943c). No primeiro deles Candido escreveu, atiçando: "Desde já, é fora de dúvida que o famoso "Marco Zero", que aí vem, vai decidir as relações do seu autor com a posteridade" 4 (1943a). E nessa toada seguiu perfilando o artista: "Desde Vinte que ele vem fazendo barulho, provocando movimentos, suscitando definições,

\footnotetext{
${ }^{3}$ Dada a multiplicidade de exemplos extraídos da obra de Antonio Candido, por necessidade desta leitura, no critério padrão exigido para as citações (nome do autor, data e número de página) no corpo do texto, o nome do autor será utilizado uma única vez. No caso específico, para evitar repetições desnecessárias, constarão das demais ocorrências: data de publicação da obra e página a ela correspondente. As informações completas sobre as obras encontram-se em "Referências bibliográficas".

4 Os artigos do rodapé literário, publicados na Folha da Manhã, foram cedidos por Antonio Candido à A., em cópia xérox.
} 
lançando epigramas, fazendo piadas - com um dinamismo de grande estilo. Ora, uma vez corridos os anos e acalmado o rodamoinho feito pelo sr. Oswald de Andrade, o que sobrará de definitivo na sua obra?" (1943a). Com essas considerações em tom provocador, o crítico optou por uma avaliação mais geral da obra de Oswald, e, diga-se, saindo do prumo de seus escritos, nela manifestou juízos imprecisos e um tanto evasivos como se lê no trecho extraído da primeira investida, "Romance e expectativa":

A sua ex-"Trilogia do exílio", atual "Os Condenados", é claro que não lhe assegura lugar de relevo. Quanto às "Memórias de João Miramar", confesso francamente que nunca as li, por nunca ter conseguido encontrar essa raridade. O "Serafim Ponte Grande" é um belo livro, não há dúvida. Mas... Talvez estique demais a corda da piada que acaba por não mais ressoar, e compromete o significado do livro. E lhe dá um certo instantaneísmo incompatível com a duração. Por isso é que considero "Marco Zero" como a prova definitiva do trêfego sr. Oswald de Andrade. E já não é sem tempo. (1943a)

No segundo artigo, "Antes do Marco Zero", Antonio Candido avançou, perfilando atitudes do escritor, com temerária ponta de galhofa, embora acenasse com advertências pertinentes contra possíveis equívocos:

[...] no sr. Oswald de Andrade, pois, antes de mais nada, e em atenção aos escoliastas do futuro, é preciso destrinçar o personagem de lenda do artista e do escritor. Que há uma mitologia andradina, não há dúvida. Mitologia um tanto cultivada pelo seu herói e que está acabando por interferir nos julgamentos sobre ele, tornando quase impossível ao crítico contemporâneo considerar objetivamente a produção separada do personagem, que vive gingando atrás e na frente dela, a desperdiçar no farol o seu sarcasmo já meio secular. (1943b)

E mais. Num movimento atenuante, que não apagava rastros do termo "trêfego" aplicado em seu artigo anterior, reforçava a necessidade de cautela e distanciamento crítico, principalmente para os leitores do futuro:

Poucos escritores serão tão deformados pela opinião pública e pela incompreensão de seus confrades. Por culpa dele mesmo, em grande parte, conforme disse. É bom que os historiadores futuros da literatura fiquem sabendo que há, pelo menos, três Oswald de Andrade a serem considerados: o homem de Vinte e Dois, da Antropofagia; o lendário papão do burguês e o escritor. (1943b)

Com sua verve sempre de prontidão, Oswald, não deixou por menos as cutiladas do crítico e, num artigo de jornal de mesmo nome, "Antes do 
Marco Zero", desfiou sua trajetória artística e, com devida razão, afirmou seu papel proeminente no movimento modernista, evidenciando a apreciação lacunar, e por vezes comprometedora de Antonio Candido a respeito de sua obra. Na resposta Oswald escancarou as omissões e rebateu incisivo: "Ele não deu nenhuma atenção no seu balanço, à minha obra poética nem à profecia de meu Teatro. Outros darão. Para ele será falho Serafim Ponte Grande. Mas outros possuem os códigos úteis à exegese desse gran-finale do mundo burguês entre nós" (ANDRADE, 1972, p. 45). E prosseguiu, entre sério e caçoísta, como de hábito, aproveitando os tropeços de certas afirmações e oferecendo de empréstimo Memórias sentimentais de João Miramar (que o crítico atacara, confessando não ter lido). Por certo não perdeu a oportunidade de evocar o apelido que lavrara, estocando: "Antonio Candido e seus chato-boys". Dois meses depois saiu o último artigo, "Marco Zero", com mais uma avaliação restritiva do crítico. Desta vez, Oswald não retorquiu.

O revide argumentativo do escritor, direta ou indiretamente, levou Antonio Candido a repensar sua postura piadista inadvertida e a reverter aquela atitude precipitada num exame acurado da obra de Oswald, desta feita dando precedência à objetividade, com seriedade e vigor no domínio de ofício. Com essa viravolta dava demonstração pública de espírito autocrítico e de envergadura profissional. Assim procedeu na reavaliação feita meses depois em "Estouro e libertação" (1944), texto que foi incluído no primeiro livro do crítico, Brigada ligeira (1945). Nessa nova leitura Candido refundiu os artigos, reviu as falhas e aprimorou juízos no intuito de dimensionar com propriedade a produção artística de Oswald e atestar a sua relevância na vida cultural do país. Com respeito à produção ficcional do escritor, seu objetivo, dividiu o conjunto em três etapas: $1^{\mathrm{a}}$. Trilogia do exílio; 2a. Miramar /Serafim; 3a . Marco Zero I). Esboçou, então, diretrizes críticas que contemplavam a apreensão do fenômeno literário, o contexto cultural e especificidades estéticas da produção ficcional de Oswald (CANDIDO, 1975, p. 30-1).

Anos mais tarde, em "Digressão sentimental sobre Oswald de Andrade", Antonio Candido comentou seus antigos posicionamentos no rodapé literário, dando a seguinte explicação: “Os meus dois primeiros artigos, relidos depois de tanto tempo, são cheios de erros e têm aquela agressividade misturada de condescendência que parece tão oportuna aos vinte e cinco anos" (Idem, 1995, p. 69). Com respeito a Marco Zero, ponderou: "O autor ajudava o crítico a errar; e este não percebia que o que viesse viria por acréscimo", concluindo que "a expectativa produziu distorção de juízo" (p. 71). Ao longo dos anos, em diferentes oportunidades, Antonio Candido continuou escrevendo e se posicionando sobre a vida e a obra de Oswald de Andrade, de quem foi, além de polemista e crítico, amigo, compadre e testamenteiro. 
Visto em perspectiva não há como negar a viravolta, com salto qualitativo, nas leituras do crítico sobre a ficção de Oswald, que já em "Estouro e libertação" (1944) daria mostras desse processo de mudança, principalmente na abordagem de Memórias sentimentais de João Miramar (que finalmente leu) e na de Serafim Ponte Grande (relido com empenho), a seu ver, duas obras-primas representativas do estilo sério-cômico do autor. Nesse novo exame avaliou que, na segunda etapa (como designou),

tudo é diferente, desde a linguagem nua e incisiva, toda concentrada na sátira social, até a despretensão da atitude literária, despreocupada em aformosear a vida. Opõe-se ferozmente à primeira, com um tom másculo de revolta, sátira, demolição, subversão de todos os valores, esboçados nas admiráveis Memórias sentimentais de João Miramar e culminando no fragmento de grande livro que é o Serafim Ponte Grande. (1992, p. 19)

Naqueles anos de 1940, o reconhecimento apresentado com a devida valoração crítica agradou em cheio o escritor e o levou a uma reaproximação definitiva. De acordo com Candido o encontro se deu entre 1945 e 46, na Livraria Jaraguá. A iniciativa foi de Oswald. Na oportunidade, ele "propunha consolidar a nossa amizade e declarava que dali em diante eu ficava com a liberdade de escrever o que quisesse a respeito de sua obra, que ele não se molestaria nem responderia" (1995, p. 71). Assim ficou para trás a página de mal entendidos, prevalecendo a fina percepção crítica que já se projetava no reconhecimento de estreantes como Guimarães Rosa, João Cabral de Melo Neto, Clarice Lispector, como comprovam seus rodapés jornalísticos. Hoje, percorrendo a vasta produção crítica de Antonio Candido, é possível afirmar com toda segurança que Oswald nela emerge como a figura da literatura brasileira (autor e obra) sobre quem o crítico mais voltou a sua atenção. São ensaios, longas passagens em livros, estudos em coletânea, artigos em jornais, prefácio, entrevistas, palestras, depoimentos. Lido e relido, em seus pontos altos e frágeis, sem fazer concessões.

Suas leituras analítico-interpretativas sobre o artista e sua obra sempre se abrem para um campo não explorado, como exemplifica o conciso "Oswald viajante" (1954), texto depois incluído em O observador literário (1959), em que divisa o tema da mobilidade, que intuiu e confirmou por exame detido como um tópico essencial da vida e da produção ficcional do artista, nele considerando "o sentido da viagem como experiência do espírito e do sentimento nacional" (1995, p. 63). Nessa abordagem Antonio Candido põe em movimento sua profícua reflexão concernente às correlações entre o externo e o interno na obra literária. Assim, nesse penetrante sumo exploratório de Miramar, observa que "o seu estilo, no que tem de genuíno, é movimento constante, rotação das 
palavras sobre elas mesmas; translação à volta da poesia, pela solda entre fantasia e realidade, graças a uma sintaxe admiravelmente livre e construtiva" (1995, p. 63). Anos depois retoma o escritor em "Digressão sentimental sobre Oswald de Andrade", por exame minucioso da produção e da vida do artista. O texto estará na $1^{a}$ edição de Vários escritos (1970). Outras leituras encorpam o rol de publicações. Três delas incluídas em Recortes, a saber: "Os dois Oswalds", texto em que reconhece no escritor seu lado "espontâneo e intutivo, mentalmente brilhante, mas pouco ordenado. Por isso nunca procurou domar racionalmente o jogo das contradições" (1993, p. 35). Segue-se "Oswaldo, Oswáld, Ôswald", em que pretende restabelecer a origem francesa do nome do escritor (extraído de um personagem do romance Corinne de Madame de Stäel) e ao mesmo tempo recriminar o equívoco abusado da pronúncia americanizada, disseminada por modismo e por desinformação. Para completar esse conjunto de textos breves, fixados em Recortes, temos "O diário de bordo", uma sensível rememoração, em que evoca a figura de Oswald pelos caminhos de $O$ perfeito cozinheiro das almas deste mundo (1918), inicialmente motivada pela edição fac-similar (1987) do diário coletivo da garçonnière, que Candido filtra em detalhes na sua precisa descrição, registrando "que é verdadeiro prodígio gráfico, reproduzindo exatamente o amarelado do tempo, as manchas, os recortes colados, os rabiscos soltos, a cor das tintas de escrever: roxo, verde, vermelho" (1993, p. 47). Nesse artigo, percorrendo labirintos da memória, também reavivou um encontro entre os dois amigos no bairro onde morava Antonio Candido. Relata, então, que caminhando ao lado de Oswald pela rua, para ajudá-lo a pegar um táxi, foi tomado por um devaneio momentâneo que o transportou para cenários de Os condenados: "Foi apenas um segundo, durante o qual senti sem poder explicar que estávamos ambos no mundo da sua narrativa" (1993, p. 49).

No repertório de seus textos sobre Oswald, Antonio Candido confirmou com ênfase o protagonismo do artista na fermentação do movimento modernista, ao mesmo tempo mostrando a relevância de suas experimentações estéticas, procurando delas extrair características inovadoras. Num texto redigido em 1950, por exemplo, intitulado "Literatura e cultura - de 1900 a 1945" (mais tarde publicado no livro Literatura e sociedade), o crítico sublinhou o vanguardismo da "prosa telegráfica e sintética" de Memórias sentimentais de João Miramar que, para ele, "avança a cada instante rumo à poesia" (1973, p. 123). Em outro texto, como o alentado "Dialética da malandragem", publicado em $O$ discurso e a cidade, Antonio Candido estabelece a linhagem de nossa comicidade irreverente, em que inscreve Memórias de um sargento de milícias, de Manuel Antônio de Almeida, situando essa obra num quadro de ruptura da ordem burguesa, nela detectando "uma realidade válida para lá, mas também para cá da norma e da lei" (1993, p. 53). Em sua argumentação assevera que essa mobilidade cômica, atrelada à tradição popular, passa por 
Gregório de Matos, por Manuel Antônio, “até alcançar no Modernismo as suas expressões máximas, com Macunaíma e Serafim Ponte Grande" (p. 53). Suas referências não param por aí. Em Presença da literatura brasileira (1964) III, por exemplo, no volume dedicado ao Modernismo ${ }^{5}$ condensa reflexões sobre o escritor e sua obra, seguidos de fragmentos extraídos de Memórias sentimentais de João Miramar (1924), poemas de Pau Brasil (1925) e de Primeiro Caderno de poesia do aluno Oswald de Andrade (1927), além da reprodução do "Manifesto Antropófago" (1928). Seguindo orientações editoriais pré-estabelecidas na estruturação da coletânea, Candido também traçou um esboço biográfico-artístico de Oswald, registrando que ele "foi uma espécie de preparador do Modernismo, sugerindo a ruptura com os velhos padrões, estimulando rebeldias estéticas, agitando o meio no sentido de uma mudança cujos rumos não discernia claramente, embora a sentisse indispensável" (1974, p. 63). Neste resumo, explica: "Na obra propriamente criadora, mostrou a importância das experiências semânticas e o relevo que a palavra adquire, quando manipulada com o duplo apoio da imagem surpreendente e da sintaxe descarnada. Deste modo quebrou as barreiras entre poesia e prosa, para atingir a uma espécie de fonte comum da linguagem artística. Pode-se dizer que a sua importância histórica de renovador e agitador (no mais alto sentido) foi decisiva para a formação da nossa literatura contemporânea" (p. 64).

Nessas explorações de fatura crítica Candido não buscou apagar fragilidades de Os condenados (1922), prosa inaugura de Oswald, que tinha sido objeto de crítica no seu já distante rodapé literário. Entre as restrições problematizou o convívio conflitante de passadismo e inovações formais, argumentando: "O estilo é excessivamente elaborado e o esteticismo lembra D'Annunzio e Oscar Wilde, mas já manifesta a técnica sincopada e composição por blocos, o senso da elipse, o dom da anotação rápida e o poder metafórico, base dos seus dois grandes livros modernistas" (p. 63). Nesse complexo processo analítico, imprimem-se marcas da leitura dialética de Antonio Candido, que equaciona sua crítica operando confrontos, identificando campos de tensões, aflorando contradições.

Nessa fecunda exploração da obra de Oswald, pode-se também encontrá-lo em Introdução à literatura brasileira. E, uma vez mais, o crítico assegura: "O grande agitador do Modernismo foi Oswald de Andrade (1890-1954), que todavia nunca realizou a fusão dos elementos contraditórios que dividem a sua obra [...]" (1997, p. 73). Nessa prospecção que traz para a roda a contribuição da fase modernista, Antonio Candido centrou parte de seu interesse no "primitivismo" que, no seu entender, "levou Oswald de Andrade a uma interpretação fecunda da cultura

\footnotetext{
${ }^{5}$ A coletânea Presença da literatura brasileira é assinada por Antonio Candido e José Aderaldo Castello. Apesar dos debates estabalecidos entre os autores, a elaboração do volume I, sobre o período Colonial ficou a cargo de J.A. Castello; o III, dedicado ao Modernismo, foi elaborado por Antonio Candido.
} 
brasileira como assimilação destruidora e recriadora da cultura europeia com vistas a uma civilização desrecalcada e anti-autoritária, cujo marco se encontra no importante 'Manifesto Antropófago' (1928)" (p. 73-4) Dando continuidade à sua apreciação sobre o tema, seguindo a linha temporal, Candido registrou que depois da ruptura com o Partido Comunista Oswald "retomou as ideias da Antropofagia com vistas à sua velha luta contra o autoritarismo, expresso na imagem do pai e nos sistemas sociais que a prolongam, contra os quais fez a apologia do matriarcado" (p. 74). Com isso, uma vez mais, o crítico deu guarida à atuação rebelde de Oswald, por um tema que o interessou desde os anos de 1920 e prosseguiu pela vida, como comprova uma nota de Candido encontrada por Vinicius Dantas ao pesquisar escritos de Oswald nos arquivos do IEB (USP). Esse recorte breve, mas muito relevante, tinha sido publicado na revista Paralelo em 1947, acompanhando a reprodução de uma entrevista de Oswald concedida a Paulo Mendes Campos, então recém-saída no Diário Carioca (cf. 1990, p. 121-32). Seguindo a nota de Antonio Candido, na mencionada revista Paralelo, o cerne da Antropofagia oswaldiana seria "o sentimento, por ele comunicado, de que o mais importante é decantar, nos produtos complexos da 'cultura da servidão', as partículas inestimáveis de liberdade, ou seja, depurar o movimento revolucionário, indo buscá-lo onde estiver - na sinfonia, na equação ou no gesto - integrá-lo, livre de ganga, no gráfico ascendente que busca a 'cultura de liberdade'" (2006, p. 172) Com base nesse pensamento inovador de Oswald, o crítico expõe sua interpretação, explicitando que "matriarcado e homem natural não significam para nós categorias históricas ou culturais concretas, mas metáforas ativas, que validam uma aspiração ascendente de humanização. E [prossegue] como julgamos a metáfora uma força criadora, a par do conceito e da ação, consideramos da maior importância, para os novos, o testemunho de Oswald" (p. 172).

O tema da antropofagia voltará, anos mais tarde, no artigo "Uma palavra instável" (1984), nutrindo uma reflexão substantiva (e muito atual) de Antonio Candido sobre significados flutuantes (flexíveis e temerários) do termo "nacionalismo", historiando e analisando seus usos no curso do século XX. Nessa sondagem o crítico retoma ideias de Oswald de Andrade e conclui que ele "exprimiu brilhantemente na teoria da Antropofagia todo esse movimento, ao sugerir que a nossa maneira de fazer cultura era devorar a europeia, a fim de transformá-la em carne e sangue nossos" (1995, p. 299). Como entendido por ele em 1947, renova a ideia de que para Oswald a "antropofagia tem uma qualidade onívora e não escolhe para devorar: o ato de devorar é que vai expelindo os detritos; o alimento para ele é sempre bom se for certa a maneira de comer" (2006, p. 172). Por esse modo de assimilar, que implica o bom aproveitamento do que foi deglutido, Oswald segue a vertente do "nacionalismo crítico", em choque com posições ufanistas, ingênuas ou não, assumidas por certos integrantes 
do movimento modernista. Sem esquecer esse e outros elementos de contradição, presentes no referido movimento, Antonio Candido ajuíza que "o Modernismo foi um momento crucial no processo de constituição da cultura brasileira, afirmando o particular do país em termos tomados aos países adiantados". E, ajunta: "Mais do que ninguém, os modernistas fizeram sentir a verdade segundo a qual só o particular se universaliza [...]" (1995, p. 299). Pelo que se depreende desse conjunto de leituras, o Modernismo brasileiro também foi uma rica fonte de reflexão para Antonio Candido, tanto servindo para a compreensão da arte como do país, procedendo principalmente de diálogos com a obra de Oswald e com a de Mário de Andrade, retendo questionamentos que nutrem uma de suas formulações singulares, a função determinante do "particularismo literário na dialética do local e do cosmopolita" (1973, p. 112). Essa relação dinâmica, exposta em Literatura e sociedade, chamou atenção de críticos latinoamericanos como Ángel Rama e Beatriz Sarlo.

E é na esfera do Modernismo brasileiro que Candido situa a obra revolucionária de Oswald, e a reconhece como um dos prumos do movimento. No campo das ousadias formais, que moldam a experiência estética do artista, tomou como exemplo Memórias sentimentais de João Miramar, entendendo que nela "a realidade é trabalhada por meio de recursos poéticos, com apelo à sugestão, à alusão, à metáfora e ao trocadilho" (1984, p. 25). Na sequência imediata, argumenta que "estes processos se aliavam a uma espécie de estética do fragmentário, com espaços brancos na composição tipográfica e na própria sequência do discurso, procurando dividir a realidade em blocos sugestivos, cuja unificação é feita no espírito do leitor, dispensando a rigorosa concatenação lógica" (p. 25). Desse modo Antonio Candido segue desentranhando das audácias formais de Miramar uma vasta gama de procedimentos estéticos por meio dos quais, segundo capta, Oswald tece sua leitura do país. A essa altura, não é demais lembrar que certas facetas dessa elaboração analítica remontam a "Estouro e libertação", como se pode conferir na exposição de Antonio Candido:

Memórias sentimentais de João Miramar, além de ser um dos maiores livros da nossa literatura, é uma tentativa seríssima de estilo e narrativa, ao mesmo tempo que um primeiro esboço de sátira social. A burguesia endinheirada roda pelo mundo o seu vazio, as suas convenções, numa esterilidade apavorante. Miramar é um humorista pince-sans-rire que (como se diria naquele tempo) procura kodakar a vida imperturbavelmente, por meio de uma linguagem sintética e fulgurante, cheia de soldas arrojadas, de uma concisão lapidar. Graças a esta linguagem viva e expressiva, apoiada em elipses e subentendidos, Oswald consegue quase operar uma fusão da prosa com a poesia. $(1995$, p. 52)

Nesse mesmo artigo de 1944, Antonio Candido também deu visibilidade à irreverência combativa de outra obra da ficção 
revolucionária de Oswald, Serafim Ponte Grande, que definiu como "antítese da atitude parnasiana". Assegurou ainda que Serafim formava com Miramar "a fase da negação" (1995, p. 52) na produção ficcional do artista. Nela também estará presente o tema da viagem, que Candido considerou um ponto nevrálgico na vida e na obra do escritor. Na sua avaliação, a Europa representou para ele uma experiência marcante porque "viajar para ele é não apenas buscar coisas novas, mas purgar as lacunas de sua terra" (p. 62). E, ao compreender que viajar foi para Oswald "um meio de conhecer e sentir o Brasil, transfigurado pela distância" (p. 62), Candido também confere dimensão mais ampla, aprofundada e unitária da notável percepção de Paulo Prado no prefácio de Pau Brasil (1925), para quem essa poesia era "o ovo de Colombo". Assim, na sua visão cirúrgica: "Oswald de Andrade, numa viagem a Paris, do alto do atelier da Place Clichy - umbigo do mundo - descobriu, deslumbrado, a sua própria terra" (PRADO, 1924, p. 5).

Atento ao tema da "mobilidade", que concebe atrelado ao da "libertação", Antonio Candido formula, ainda, uma leitura desbravadora de Serafim Ponte Grande. E, em mais uma análise certeira dessa obra de difícil penetração crítica, Candido segue o fluxo rebelde da invenção oswaldiana, afirmando que nela "a crosta da formação burguesa e conformista é varrida pela utopia da viagem permanente e redentora, pela busca da plenitude através da mobilidade" (1995, p. 64). Neste sentido, sublinha a função essencial e o valor estético da "estrutura instável" da obra que, no seu entender, dimensiona "a estética transitiva do viajante", apresando o mundo por fragmentos. A isso Antonio Candido concebe a agitação libertária como um modo de bombardear a rotina, enfocando por esse viés outro ponto fulcral de Serafim Ponte Grande - o capítulo "Os antropófagos". Nesse episódio a realização da viagem permanente do navio El Durazno é entendida como a soma total dos navios que, na obra, "vão saindo da realidade para entrar nos mares do sonho" e, por isso, mesmo El Durazno, "navega como um fantasma solto, evitando desembarques na terra firme da tradição" (1995, p. 64). Para o crítico o navio "encarna o mito da liberdade integral pelo movimento incessante, a rejeição de qualquer permanência" (p. 65). No seu entendimento, adentrando camadas profundas de Serafim Ponte Grande, essa libertação se dá "sob a forma bocagiana de uma rebelião burlesca dos instintos" (p. 65). Por esse filão Antonio Candido também traz para o repertório de escritos sobre as utopias, já no final da vida do escritor, "em que [Oswald] procura conforto para o nosso tempo, refundindo os ideais da sociedade perfeita, ligados às grandes viagens que inauguram a Idade Moderna" (p. 65). Em "Oswald viajante", produzido sob o impacto da morte do escritor, o crítico desafoga: "E quando lembramos que está morto, pensamos involuntariamente que partiu para mais uma viagem, buscando novos mundos para a sua fome antropofágica de sonho e liberdade" (p. 66). Os 
exemplos servem para dimensionar a interpretação de Antonio Candido segundo a qual a vida de Oswald de Andrade seria tão importante quanto a sua obra. Mas, atento às facilidades, é dele também o alerta de que não se pode perder de vista o horizonte crítico. Assim, avalia que para entender esse "bicho papão do burguês" é preciso separar "o escritor do personagem da lenda", quase sempre "deformado pela opinião pública". Como antevisto, confirma-se o que escreveu no distante 1944, "Oswald de Andrade é um problema literário. Imagino, pelas que passa nos contemporâneos, as rasteiras que passará nos críticos do futuro" (p. 41).

Por fim, lembrando seu convívio próximo com o artista, anota-se que partiu de Antonio Candido a ideia (ou intimação) para que Oswald escrevesse suas Memórias. Da insistência resultou o único volume que o artista, já bastante doente, alcançou concluir - Um homem sem profissão. Sob as ordens de mamãe - publicado em 1954, mesmo ano de sua morte. Na abertura desse relato Oswald escreveu: "Hoje, feriado, 15 de Agosto, vieram almoçar conosco os casais Antonio Candido e Domingos Carvalho da Silva". Na sequência, dará crédito ao conselho do amigo, declarando: "Antonio Candido diz que uma literatura só adquire maioridade com memórias, cartas e documentos pessoais e me fez jurar que tentarei escrever já este diário confessional./ Pois, se é preciso começar, comecemos pelo começo" (ANDRADE, 1954, p. 23). Assinando a introdução dessa obra, em "Prefácio inútil", Antonio Candido retomou o tema da mobilidade, afiançando que em Um homem sem profissão Oswald realizou uma "viagem interior à busca das raízes do seu ser inquieto e agitado" (CANDIDO, 1995, p. 65). Ainda, para dar conta do universo da obra, retomou uma chave-mestra por ele acionada, via Baudelaire, em "Oswald viajante" - a da lâmpada pueril que faz "o mundo parecer grande" com a da fantasia que se retrai na vida adulta pela força inexorável do mundo real. Essa visão da criança, segundo o crítico, é preservada nos poetas, como é o caso [diz ele] de Oswald de Andrade. Nesse texto, escrito sob o impacto da perda do amigo, Antonio Candido nele destacou a "fome antropofágica de sonho e liberdade" (1995, p. 66). Em outra passagem, do mesmo texto, gravou com sensível percepção e conhecimento de causa que "as Memórias esclarecem a aventura lírica de Oswald de Andrade, gordo Quixote procurando conformar a realidade ao sonho. Daí a rebeldia dos que não aceitam a ordenação média dos atos pela sociedade, que criou em torno dele, como represália, a aura de maluco atirando contra tudo, contra todos" (ANDRADE, 1954, p. 11).

Os escritos de Antonio Candido sobre Oswald de Andrade são até hoje essenciais para o estudo da vida e da obra do artista, que também se funde na compreensão do nosso Modernismo e na visão crítica abrangente da cultura e da história do Brasil contemporâneo. Além dessa contribuição decisiva, Antonio Candido atuou como um importante difusor do movimento modernista e de seus integrantes. Na década de 1960, por 
exemplo, ele foi o primeiro professor a levar para a sala de aula o movimento de 22 e a introduzir no currículo universitário defasado seus autores e obras, alcançando validar e impulsionar devidamente esse campo de estudos. Também reafirmou esse empenho norteando projetos de pesquisa para o estudo do Modernismo e de seus principais autores, como se confere em dissertações e teses de grande parte de seus orientandos.

\section{Referências bibliográficas}

ANDRADE. Oswald de. "Antes do Marco Zero". In: Ponta de lança. Rio de Janeiro: Civilização Brasileira, 1972, p. 42-7.

ANDRADE. Oswald de. Um homem sem profissão: sob as ordens de mamãe. Rio de Janeiro: José Olympio, 1954.

ANDRADE. Oswald de. "Entrevista a Paulo Mendes Campos". In: Os dentes do dragão (título atribuído pela org. Maria Eugenia Boaventura). São Paulo: Ed. Globo, 1990, p. 121-32.

CANDIDO, Antonio. Folha da Manhã. São Paulo: "Romance e expectativa" (8 ago. 1943); "Antes do Marco Zero" (15 ago. 1943); e "Marco Zero" (29 out. 1943).

CANDIDO, Antonio. "Prefácio inútil". In: ANDRADE, Oswald de. Um homem sem profissão: sob as ordens de mamãe. Rio de Janeiro: José Olympio, 1954, p. 9-15.

CANDIDO, Antonio. "Literatura e Cultura - de 1900 a 1945". In: Literatura e sociedade. São Paulo: Companhia Editora Nacional, 1973, p. 109-38.

CANDIDO, Antonio e CASTELLO, José Aderaldo. Presença da Literatura Brasileira. III. Modernismo. São Paulo: Difusão europeia do livro, 1974.

CANDIDO, Antonio. "Pressupostos". In: Formação da Literatura Brasileira. São Paulo /Rio de Janeiro: Edusp; Itatiaia, 1975, p. 30-1.

CANDIDO, Antonio. "Dialética da malandragem". In: O discurso e a cidade. São Paulo: Duas cidades, 1993, p. 19-54.

CANDIDO, Antonio. Introdução à literatura brasileira (resumo para principiantes). São Paulo: Humanitas, 1997.

CANDIDO, Antonio. "Estouro e libertação" (p. 41-60); "Oswald viajante" (p. 61-6); "Digressão sentimental sobre Oswald de Andrade" (p. 67-103); "Uma palavra instável" (p. 293-305). In: Vários escritos. São Paulo: Duas cidades: 1995 ( $3^{\text {a }}$ ed. revista e aumentada).

CANDIDO, Antonio. "Estouro e libertação". In: Brigada ligeira e outros escritos. São Paulo: Ed. Unesp, 1992, p. 17-32.

CANDIDO, Antonio. "Os dois Oswalds" (p. 35-42); "Oswaldo, Oswáld, Ôswald" (p. 43-6); "Diário de bordo" (p. 47-9). In: Recortes. São Paulo: Companhia das letras, 1993. 
CANDIDO, Antonio. "Nota da redação". In: CARA, Salete de Almeida e ABDALLA JR., Benjamin (orgs.). Moderno de nascença: figurações críticas do Brasil. São Paulo: Boitempo, 2006, p. 171-2.

PRADO, Paulo. "Poesia Pau Brasil". In: ANDRADE, Oswald de. Pau Brasil. Paris: Sans Pareil, 1925, p. 5-13.

Maria Augusta Fonseca é professora livre-docente sênior do Departamento de Teoria literária e Literatura Comparada da Universidade de São Paulo. É autora de Palhaço da burguesia: Serafim Ponte Grande e o universo circense (1979); Oswald de Andrade: o homem que come (1982, 2a ed.); Oswald de Andrade: biografia (2007, 2a ed.); Por que ler Oswald de Andrade (2008); Por que ler Mario de Andrade (2013), e organizou, com Roberto Schwarz, Antonio Candido 100 anos (2018). Contato: mabfonseca@uol.com.br

ORCiD: https:// orcid.org/0000-0003-2738-9485 